\title{
Almansba, Franchini and Sterkowicz Judo Specific Test Proposal (2007) Commentary
}

\author{
André Mukala Nsengu Tshibangu \\ Department of Basic Sciences, Faculty of Pharmaceutical Sciences, University of Kinshasa, Kinshasa, \\ Democratic Republic of the Congo \\ Email: andrem36@hotmail.com
}

How to cite this paper: Tshibangu, A.M.N. (2018) Almansba, Franchini and Sterkowicz Judo Specific Test Proposal (2007) Commentary. Open Journal of Molecular and Integrative Physiology, 8, 13-28. https://doi.org/10.4236/ojmip.2018.82002

Received: April 14, 2018

Accepted: May 28, 2018

Published: May 31, 2018

Copyright $\odot 2018$ by author and Scientific Research Publishing Inc. This work is licensed under the Creative Commons Attribution International License (CC BY 4.0).

http://creativecommons.org/licenses/by/4.0/ Open Access

\begin{abstract}
The present commentary is aimed to contribute to the improvement of the judo specific test proposal elaborated and validated by Almansba, Franchini and Sterkowicz (2007) 1) with the aim of evaluating specifically the physical fitness of competing judo practitioners, 2) wishing the test to be representative both qualitatively and quantitatively of the effort sustained by the practitioners. All alone, the test proposal, which utilizes rapid repetitions of one judo technique off-balancing and body positioning by the same practitioner (Uchi-komi) may be usable instead of three non-judo specific tests: the vertical jump test of Sargent (1921), the multistage fitness test of Léger et al. (1984) and the Australian shuttle run test described by Cazorla et al. (2004). However, the judo specific test proposal 1) specificity is still to be increased and must ideally turn into test individualization (using the proposal as a template), as in judo, trained individuals have favorite techniques they use in preference to others; 2) represents competing judo practitioners efforts quantitatively but not qualitatively (throws are represented, but neither hold downs, arm-locks, strangle holds nor chokeholds); 3) brings subjects to physiological exhaustion but psychological exhaustion emotional component is left out of account. Uchi-komi utilized by the test proposal could better be replaced by continual completions of variable judo techniques by the same practitioner (Kakari-geiko) which allow the practitioner who is attacking by means of judo techniques (Tori) to utilize linked up techniques. Nevertheless, to date, the test proposed for assessing the suitability of judo practitioners to meet competition demands is the most judo specific and the most economic.
\end{abstract}

\section{Keywords}

Fitness Evaluation Test, Judo, Martial Art, Musculoskeletal Physiology 


\section{Introduction}

In October 2007, Almansba, Franchini and Sterkowicz published an article titled "Uchi-komi avec charge, une approche physiologique d'un nouveau test spécifique au judo [An Uchi-komi with load, a physiological approach of a new special judo test proposal]" [1].

The article has been among the most downloaded of the journal that published it. That witnesses both the curiosity it has raised and probably a need previously existing in the judo practitioner physiological capacities determination, need that the article content meets.

The objective to achieve while dealing with their research work is defined in the article both at the end of the introduction and almost at the end of the material and methods: to elaborate and to validate a specific test usable to evaluate the physical fitness of the competing judo practitioner, a test representative both qualitatively and quantitatively of the effort sustained, what implies among other things that at the end of the test, judo practitioners have to reach physical, physiological and psychological exhaustion.

The present commentary is aimed to comment the aforementioned authors test proposal so as to contribute to improvement of the latter.

\section{Material and Methods}

\subsection{Material}

The various elements subject of the present commentary are found in the introduction, the material and methods, the discussion, as well as the conclusion of the article published by Almansba, Franchini and Sterkowicz [1].

The introduction is comprised of the description of a judo practitioner exercise [rapid repetitions of one judo technique off-balancing and body positioning by the same practitioner (Uchi-komi)], of data on judo fight as well as of commentaries 1) on combat sports physical performance evaluation tests, 2) on a judo competition physical performance evaluation, and 3) on a judo specific device for bodybuilding.

The material and methods present the subjects enrolled for the elaboration and validation of the judo specific test proposal concerned in the present commentary, the anthropometric techniques that have been used for that purpose, the description of a few non-specific sporting physical performance evaluation tests as well as the description of the judo specific test proposal.

The discussion is concerned with the representativeness, the sensitivity and the validity of the judo specific test proposal.

The conclusion 1) summarizes arguments that, according to the authors, allow them state the specificity, the representativeness, the sensitivity and the validity of their judo specific field test proposal; as well as it 2) speaks of the possibility of utilizing the test proposal in monitoring the judo practitioner physical fitness level and adjusting the practitioner physical preparation better than laboratory tests. 


\subsection{Method of Commenting}

With the aim of commenting the article which is object of the present annotations, consideration has been given to what has previously been reported on physical exercise and sport, in general, as well as what has previously been reported on judo, in particular.

\subsection{Commentaries of Different Parts of the Article Here Commented}

With the exception of the results, the four other parts (introduction, material and methods, discussion and conclusion) of the article here commented are successively the object of the commentary.

When a same subject has appeared more than once in the five parts of the article commented, for each part, the commentary, as far as possible, has been about the object of the part: for instance, 1) the definition of the adjective 'isometric' is concerned with in the commentary of the introduction, 2) the relevance of an isometric grip style is concerned with in the commentary of the material and methods, 3) an isometric grip style representativeness, speaking of the effort sustained during a judo fight, is concerned with in the commentary of the discussion.

\subsection{Judo Techniques Designations}

The judo practitioner, a potential reader of the present commentary, usually calls judo techniques utilizing their Japanese designations, was the practitioner living in Kinshasa (Africa), in Madrid (Europe) and, possibly, also elsewhere.

However, the non-judo practitioner individual interested in sports sciences would better understand the reality expressed by the designations of judo techniques in the language in which the present commentary is written (English) than in Japanese.

Judo practitioners are assumed to be, as far as number is concerned, more interested in the present commentary than non-judo practitioners interested in sports sciences.

That is the reason why, in each paragraph of the commentary, if possible, the first time when the designation of a judo technique appears, it is given in English words followed by the translation in Japanese. The following times, in the same paragraph, the designation appears only in Japanese.

\section{Results and Discussion}

\subsection{Introduction of the Article Here Commented}

\subsubsection{Standing Work, Ground Work and Nature of the Effort Sustained} According to the authors, during standing work, upper limbs perform an isometric, even explosive effort.

There is no valid connection between the adjective "isometric" and the effort sustained by the judo practitioner during the standing work (Tachi-waza), 
leaving aside some exceptions such as the grip style (Kumi-kata) 1) of a frightened judo practitioner, 2) of a judo practitioner who does not think to incite to his own advantage a defense reaction from the opponent by a false beginning of attack (feint), or 3) of a judo practitioner who does not think to avoid energy mismanagement by varying the force of his Kumi-kata from a loose basal one.

In fact, with the exception of the unusual times when the judo practitioner benefits from the opponent spontaneous imbalance, mostly he does put the opponent out of balance, what unavoidably generates muscles lengths variations in the upper $\operatorname{limb}(s)$ utilized: the off-balancing (Kuzushi) needs a grip style (Kumi-kata) force increase and results in muscles lengths variations in the upper limbs, for instance in the angle between the forearm and the upper arm at the elbow joint.

The effort carried out that way is a dynamic (anisometric) one.

The effort performed during ground work is said to be isometric.

It strikes that the adjective "isometric" does not apply to the effort sustained during ground work (Ne-waza).

In fact, while arm locks (Kansetsu-waza $=$ Kwansetsu-waza) as well as choke holds and strangleholds (Shime-waza) must be quick-acting and produce the desired effect immediately, on the other hand, it is advised not to mismanage energy expenditure during the hold downs (Osae-komi), more frequently used than Kansetsu-waza and Shime-waza [2]: during the Osae-komi duration, the practitioner who is attempting an attack by means of a judo technique (Tori) must 1) use only the necessary force for the Osae-komi to be effective, 2) increase the force only to oppose any attempt of hold down escape (Osae-komitoketa) made by the practitioner on which has been performed an attack by means of a judo technique ( $U k e$ ), and 3 ) decrease the force immediately when Uke fails, being it question of Uke wrapping his legs around any part of Toris lower body or trunk, of Uke rolling Tori over to get on top of him, etc.

The effort sustained by both the practitioner who is attempting an attack by means of a judo technique (Tori) and the practitioner on which is being attempted an attack by means of a judo technique (Uke) is hence far from being isometric. It may even be explosive, for instance in the case that $U k e$, held down by the basic scarf hold down (Hon-kesa-gatame), escapes the hold down (Osae-komi) by an explosive movement and holds down Tori by using the same technique (Hon-kesa-gatame-gaeshi).

\subsubsection{Criticisms Leveled by the Authors at a Sporting Physical Performance Evaluation Test and a Device for Bodybuilding, Both of Them Judo Specific}

The authors 1) signal that commonly used sporting performance evaluation tests are not specific to judo, for instance the multistage fitness test of Léger et al. (1984), 2) signal an attempt of Thomas et al. (1989) [3] to adapt to judo the Léger-Mercier test (1983) and 3) reproach Thomas et al. for the fact that their 
test makes it difficult to dissociate what results from motor skill from what is the outcome of maximal oxygen consumption ( $\left.\dot{\mathrm{V}}_{2} \max \right)$.

The dissociation is of very little significance in a test aimed to assess performance-related fitness, either measuring oxygen consumption or predicting it via heart rate responses. As pointed out in the discussion, heart rate values are lower in very trained subjects when compared with less trained subjects, consistent with what has been said by McArdle, Katch and Katch [4] as well as consistent with the results obtained by the authors themselves [1].

Moreover, judo practitioners are used to choose one or a few techniques on which they rely most of the time and, consequently, they train to the most. Hence, in judo practitioners whose favorite techniques (Tokui-waza) comprise the shoulder throw (Seoi-nage), the sleeve lifting and pulling hip throw (Sodetsuri-komi-goshi), or techniques related to the two previous, motor skill is going to be higher while maximal oxygen consumption $\left(\dot{\mathrm{VO}}_{2} \max \right)$ and heart rate are going to be lower, compared with judo practitioners who possess other favorite techniques (Tokui-waza).

Motor skill is thus able to influence heart rate values and maximal oxygen consumption ( $\dot{\mathrm{VO}}_{2} \max$ ).

That is possibly a sign of weakness in the judo specific test proposed by $\mathrm{Al}$ mansba, Franchini and Sterkowicz (2007), with regard to specific characteristics of the judo practitioner favorite techniques (Tokui-waza).

The authors reproach Blais and Trilles (2006) [5] for the fact that their bodybuilding device could make the judo practitioner very reluctant to unusual exercises repetitions.

The reproach of the authors remains valid for their own test proposal: repetitions of the shoulder throw (Seoi-nage) as well as those of the sleeve lifting and pulling hip throw (Sode-tsuri-komi-goshi) imposed by their test proposal are unusual exercises for judo practitioners whose favorite techniques (Tokui-waza) do not comprise the two techniques or techniques similar to them. The latter practitioners could be reluctant to repetitions of the two techniques.

\subsubsection{Phases of Judo Fight}

The authors end the introduction of their article presenting the object of their study: to elaborate and to validate a test specific to judo practice, close to the competition, representative of the effort sustained during a judo fight at the qualitative level (respect of the different phases observed during a judo fight), as well as at the quantitative level (respect of the work sequences durations, of break, ...); all that, so as to provide the reader with the indications that testify the judo practitioner specific physical fitness and the latter's cardiovascular adaptation to an effort specific to judo practice.

However, in that introduction, the authors speak of two types of judo work phases: standing work (Tachi-waza) [they have mistakenly called Nage-waza (throwing techniques)] and ground work (Ne-waza). Meanwhile, their judo specific test takes into account only of standing work (Tachi-waza) but not of 
Ne-waza.

The judo specific test proposed by Almansba, Franchini and Sterkowicz (2007) needs hence an increase in its representativeness, regarding ground work.

\subsection{Material and Methods of the Article Here Commented}

\subsubsection{Subjects Enrolled in the Judo Specific Test Proposal Elaboration and Validation}

After the authors, the mean values of anthropometric variables show that the two groups (elite and sub-elite) homogeneity has been ensured about the age, the weight, the height, as well as about the percentage of body weight as fat-free body mass and as fat body mass.

Height homogeneity may be counterproductive, taking the aim of the test proposal into account. In fact, one may imagine how overtaxing may result performing the two-arm shoulder throw (Morote-seoi-nage) by the tallest practitioner who is attempting the attack by means of the judo technique (Tori) on the shortest practitioner on which is being attempted the attack by means of the judo technique (Uke), or how overtaxing may result performing the inner-thigh reaping throw (Uchi-mata) by the shortest Tori on the tallest $U$ ke. The presence of Uchi-mata is thus more expectable than the one of Morote-seoi-nage in the favorite techniques (Tokui-waza) of a judo practitioner used to train with partners shorter than him, and the contrary in the Tokui-waza of a judo practitioner used to train with partners taller than him. The presence of Morote-seoi-nage in the test proposal would have caused a relative high heart rate in the tallest judo practitioner performing it on the shortest judo practitioner, and a lower heart rate when replacing Morote-seoi-nage by Uchi-mata.

The influence of judo practitioner height on judo throwing techniques had already been reported and illustrated utilizing the sweeping hip throw ( $\mathrm{Ha}$ rai-goshi) and the large outer reap (O-soto-gari) both considered well-suited for large and strong judo practitioners, and the shoulder throw (Seoi-nage) considered well-suited for shorter practitioners with good agility [6].

The year following the publication of their judo specific test proposal, the authors, associated with three others researchers, carried out a work which objective was to verify if there was a difference in throwing speed performance between heavier and lighter judo weight divisions practitioners, utilizing what appeared to the researchers the most popular throws among the practitioners and the most frequently used during judo competitions [the shoulder throw (Seoinage), the large outer reap (O-soto-gari), and the inner-thigh reaping throw (Uchi-mata)] [7]. The speed was expressed as the total number of throws per time unit. The work yielded, among other results, what follows: 1) Seoi-nage speed mean value of the lighter group practitioners was higher than that of the heavier group practitioners $(\mathrm{p}<0.01)$; the number of throws was negatively correlated to the body height $(\mathrm{r}=-0.48, \mathrm{p}<0.05)$ and weight $(\mathrm{r}=-0.61, \mathrm{p}<0.05)$; 2) Uchi-mata speed mean value of the heavier group practitioners were higher than that of the lighter group practitioners $(\mathrm{p}<0.05)$; the number of throws was 
positively correlated with the body height $(\mathrm{r}=0.48, \mathrm{p}<0.05)$.

Judo practitioner height may thus make either easy or laborious performing a judo technique, influence the components of the practitioner's favorite techniques (Tokui-waza), and, hence, influence the resulting heart rate values while performing judo techniques.

\subsubsection{Performance Evaluation Tests Older Than Judo Specific Test Proposed by Almansba, Franchini and Sterkowicz (2007)}

Before describing their judo specific test proposal (2007), the authors describe three evaluation tests previously known: the multistage fitness test of Léger et al. (1984), the vertical jump test of Sargent (1921) and the Australian shuttle run test described by Cazorla et al. (2004).

Those three tests already known, utilized by the authors for the purpose of validating their judo specific test proposal, call in more the lower limbs than the upper limbs. The Sargent test even prohibits the subjects from running jump: the subjects were subjected to a standing jump.

Meanwhile, the upper limbs play a large part in a judo fight, during standing work [while performing an off-balancing (Kuzushi), for instance] as well as during ground work.

The Almansba, Franchini and Sterkowicz judo specific test proposal (2007) needs thus an increase in its judo representativeness, concerning the use of upper limbs.

\subsubsection{Almansba, Franchini and SterkowiczJudo Specific Test Proposal (2007)}

The test is comprised of 1) a 3-second grip phase during which an isometric grip style (Kumi-kata) is imposed on the subject, the judo practitioner holding with one hand a sleeve and with the other hand a lapel of a judo jacket (Judogi) hanged on a horizontal bar, and immediately after, 2) an explosive phase during which the practitioner who is attempting an attack by means of a judo technique (Tori) shuttles back and forth between two practitioners on which is being attempted an attack by means of a judo technique (Uke) so as to load each of them while performing on each a rapid repetition of one judo technique off-balancing and body positioning (Uchi-komi with load) [ the shoulder throw (Seoi-nage) on one Uke and next the sleeve lifting and pulling hip throw (Sode-tsuri-komi-goshi) on the other Uke].

The first phase of the test consists of an isometric grip style (Kumi-kata) of a judo jacket (Judogi), contrary to the combat situation where, in the aim of avoiding an useless energy waste, the practitioner who is attempting an attack by means of a judo technique (Tori) would better hold a basal loose grip that he strengthens only when he is attacking or wants to seem on the point of attacking the practitioner on which is being attempted the attack by means of a judo technique (Uke), or also when reacting against an attack beginning or an attack attempt from his opponent, with the resulting muscles lengths variations, not only in the hands but also in other parts of the upper limbs. Is one sure that, used to 
work like that, the subjects (elite and sub-elites) did not do the same during the test proposal? The authors would better have signaled due precautions that have been taken to prevent any anisometric grip.

Furthermore, the judo jacket (Judogi) on which the grip phase is achieved is not worn by a judo practitioner. Meanwhile, the dimensions of the judo practitioner who wears the Judogi could possibly influence the tension in the hands muscles of the practitioner who is attempting an attack by means of a judo technique (Tori) and thus influence Toris energy expenditure values. The hands muscles tension could decrease in the following direction: practitioner on which is being attempted an attack by means of a judo technique ( $U k e$ ) of large dimensions > Uke of small dimensions > absence of Uke. Would not it be worth replacing the horizontal bar by another judo practitioner of height and weight comparable to those of a potential opponent?

In the test proposal, during the execution of the shoulder throw (Seoi-nage) as well as during that of the sleeve lifting and pulling hip throw (Sode-tsuri-komigoshi), the grip style (Kumi-kata) remains the same: the practitioner who is attempting an attack by means of a judo technique (Tori) holds a sleeve with one hand and a lapel of the judo jacket (Judogi) with the other hand.

Speaking of the shoulder throw (Seoi-nage), the authors neither specify the variant that has been utilized to obtain the results published in their article nor state that for a given reason, their conclusions apply to each of the variants known [two-arm shoulder throw (Morote-seoi-nage), one-arm shoulder throw (Ippon-seoi-nage), lapel shoulder throw (Kata-eri-seoi-nage), (Fumi-komi-seoinage), and wrap around shoulder throw (Makikomi-seoi-nage)]. Meanwhile, during the body positioning (Tsukuri), the grip style (Kumi-kata) varies qualitatively according to the variant: 1) in Morote-seoi-nage, the practitioner who is attempting an attack by means of a judo technique (Tori)'s two hands stay in the position described by the authors for the first phase [3-second grip phase of a judo jacket (Judogi) not worn]; 2) in Ippon-seoi-nage and Fumi-komi-seoi-nage, the hand that previously held the Judogi lapel slips under the armpit on the side of Uke's still held sleeve before its corresponding arm is gripped by Toris joint that exists at the elbow of the arm that previously held the lapel; 3) in Kata-eri-seoi-nage, Tori's hands hold the Judogi sleeve and the Judogi lapel of Uke's body same side, either right or left; 4) in Makikomi-seoi-nage, Tori's arm which hand previously held Uke's lapel goes over the still held Uke's sleeve.

As for the sleeve lifting and pulling hip throw (Sode-tsuri-komi-goshi), the prefix "Sode" is due to the fact that each hand of the practitioner who is completing a judo technique (Tori) holds one sleeve different from the other. In fact, comparing with the position described by the authors for the first phase [3-second grip phase of a judo jacket (Judogi) not worn], an additional sleeve is so held: no lapel is held. The grip style (Kumi-kata) utilized in the Almansba, Franchini and Sterkowicz judo specific test proposal (2007) is hence no representative of Sode-tsuri-komi-goshi execution during a judo fight. 


\subsection{Discussion of the Article Here Commented}

\subsubsection{Representativeness of the Judo Specific Test Proposal}

The authors of the judo specific test proposal end the introduction of the article that published the proposal presenting the object of the study that led to the existence of the proposal: to elaborate and to validate a judo practice specific test, close to the competition, representative of the efforts sustained during a judo fight, at the qualitative level as well as at the quantitative level. The results presented by the authors testify to a profile similarity of the heart rate evolution between their two groups of subjects (elite subjects and sub-elite subjects) as well as between the subjects who participated, some of them in fights and others in judo specific tests elaboration.

Compared with commonly used tests for realizing whether the practitioner fulfills the requirements to enter a competition, the Almansba, Franchini and Sterkowicz test proposal (2007) is more specific to judo. As a matter of fact, the proposal utilizes the rapid repetitions of one judo technique off-balancing and body positioning by the same practitioner (Uchi-komi), a judo activity, instead of running or jumps.

However, the judo specific test proposal is not representative of the effort sustained during a judo fight, for the reasons enumerated below and some of them commented above.

1) The judo specific test proposal does not take into account the relative height of the judokas which makes either easy or laborious performing a judo technique [7], with the above mentioned influence on variables to be measured and/or to be predicted. Cf. 3.2.1. Subjects enrolled in the judo specific test proposal elaboration and validation.

2) The first phase of the test is the execution of an isometric grip style ( $\mathrm{Ku}$ mi-kata). Cf. 3.2.3. Almansba, Franchini and Sterkowicz judo specific test proposal (2007).

3) The test utilizes in its following phase two judo techniques: the shoulder throw (Seoi-nage) and the sleeve lifting and pulling hip throw (Sode-tsuri-komigoshi). Nevertheless, most of Seoi-nage variants as well as Sode-tsuri-komi-goshi resort to Kumi-kata different from that executed during the first phase of the test proposal. Cf. 3.2.3. Almansba, Franchini and Sterkowicz judo specific test proposal (2007).

4) During the execution of the two techniques imposed by the test proposal, the practitioner who is attempting an attack by means of a judo technique (Tori) releases completely the Kumi-kata and runs on a distance of four meters, contrary to the fight situation where if one hand has to release the adversary judo jacket (Judogi), the other hand maintains the hold.

5) There exist throwing techniques that resort more to upper limbs than to lower limbs. Meanwhile, the two techniques imposed by the test proposal resort more to lower limbs than to upper limbs.

a) While the execution of Seoi-nage [8] requires from lower limbs strength and lightning movement, it requires from the upper limbs a rapid action; if To- 
ri's belt has got down sufficiently under Uke's belt, Tori could throw Uke utilizing little strength, otherwise, to succeed in throwing Uke, Tori will resort to his possible possession of a lightning pep, and of strong scapula, lumbar and abdominal musculature.

b) Executing the lifting and pulling hip throw (Tsuri-komi-goshi), Tori resorts to a very strong lower limbs flexing while his hand that holds Uke's lapel must not pull but lift. It should be highlighted that in the variant "Sode-tsuri-komigoshi", the hand that previously held the lapel holds now the other sleeve (change in the Kumi-kata, change to which attention has not been drawn by the test proposal authors): the proposal authors could possibly have mistaken Tsuri-komi-goshi for its variant "Sode-tsuri-komi-goshi".

6) The judo specific test proposal utilizes only two standing work techniques but no one of the ground work techniques that exist.

7) The test is not representative of the effort sustained during judo fights by practitioners whose favorite techniques (Tokui-waza) comprise neither Seoinage or Sode-tsuri-komi-goshi, nor techniques close to those two techniques imposed by the test proposal. Cf. 3.1.2. Criticisms leveled by the authors at a sporting physical performance evaluation test and a device for bodybuilding, both of them judo specific. While exercise assessment techniques should be specific to the concerned sport since the adaptive responses to exercise are in part a function of the specific movement patterns utilized in training [9], the judo specific test proposal must take into account the existence of a given judo practitioner Tokui-waza: up to six [2] over dozens of throwing techniques (Nage-waza) [10] and, up to two [2] over dozens of submission techniques (Katame-waza) [10], what implies numerous and various movement patterns, and makes expect various quantitative influences on variables to be measured and/or to be predicted (heart rate and/or oxygen consumption, two variables taken into account by the authors to determine the exhaustion level of the judo practitioners).

8) The exhaustion determined in the judo specific test proposal derives only from physical work which, possibly, is lesser than the total exhaustion sustained by the judo practitioner during competition, total exhaustion which comprises among others an emotional component: before and all combat long, the judoka fears to be won and particularly to be won by a less ranked opponent in a sport where any attempt of attack may be turned out by the opponent to his own advantage. Meanwhile, the authors said that at the end of the judo specific test proposal, judo practitioners had to reach physical, physiological and psychological exhaustion. Cf. 1. Introduction.

\subsubsection{Sensitivity of the Judo Specific Test Proposal}

The results presented by the authors 1) show a heart rate difference between elite subjects and sub-elite subjects, so that the work asked to the judo practitioner has been more overtaxing (higher heart rate) for the sub-elite subjects than for the elite subjects (lower heart rate); 2) show a difference in the number of rapid 
repetitions of one judo technique off-balancing and body positioning by the same practitioner (Uchi-komi) between the different stages such that here also it comes to light that the work has been more overtaxing for the sub-elite subjects (smaller number) than for the elite subjects (larger number); 3) show that the aforementioned heart rate varies according to the training sessions frequency. lesser for the elite subjects who train eight to twelve times a week, and greater for the sub-elite subjects who train at the most five times a week. All that persuaded the authors of the sensitivity of their test proposal.

1) Sensitivity Taking the Judo Practitioners Training Session Levels into Account

One must wonder what should be taken into account while speaking of sensitivity expression. The results presented by the authors of the judo specific test proposal show a sensitivity of the latter in relation to the judo practitioners training session levels. However, during competitions, elite practitioners are not put against sub-elite practitioners.

Furthermore, in the introduction, the authors state that their test should be representative of the effort sustained during a judo fight. That objective seems not to be met, considering the answers given by the subjects subjected to the test proposal. Indeed, elite subjects have brought the exhaustion felt at the end of the test proposal closer to the one felt at the end of an inter-regional level judo fight. Meanwhile, the elite subjects must compete also at the international level. Consequently, the test proposal could possibly overestimate the physical fitness level of a practitioner who must enter an international competition as the test brings the practitioner only at an exhaustion level closer to that felt at the end of an inter-regional level judo fight.

Thus, speaking of exhaustion, the test is possibly representative only for sub-elite subjects (they are not obliged to enter international level competitions).

2) Sensitivity Taking the Parameters Concerned with Success in Judo Competitions into Account

Judo specific test study should be concerned with what must be measured or estimated. The test should be sensitive to values variations of the parameters concerned with success in judo competitions.

Success in judo requires a combination of parameters: a great deal of muscular strength throughout the entire body, explosive power, flexibility and, as other martial arts, agility [11].

The sensitivity of the test should be concerned with muscular strength throughout the entire body. Meanwhile, the test utilizes two judo throwing techniques which resort more to lower limbs than to upper limbs. Furthermore, the sensitivity of the test to muscular strength developed by judo practitioners during the test should not compare the values shown by elite subjects with those shown by sub-elite subjects, but rather monitor whether the judo practitioners are able to show muscular strength values representative of those shown during judo fights: the practitioner who is attempting an attack by means of a judo technique (Tori) should show muscular strength values able to overcome resis- 
tive forces generated by the practitioner on which is being attempted an attack by means of a judo technique (Uke) belonging to the same weight division as him (her), being the greatest and the least body weights of different Uke, the upper limit and the lower limit of Tori's weight division, respectively. The resistive forces here concerned are all the resistive forces that can take place during the execution of all the legal judo techniques: resistances generated by Uke while fighting against throwing techniques (Nage-waza) attempts, as well as against submission techniques (Katame-waza) or their attempts.

The judo specific test proposal has tested the execution speed of its two throwing techniques and, at the same opportunity, the related explosive power, flexibility and agility. However, the sensitivity should not be concerned with the training session levels, but rather with the parameters here concerned themselves (executive speed, explosive power, flexibility and agility).

The judo specific test proposal failed to deal with the power throughout the entire body, which power allows the judo practitioner, among other things, to slip out of a hold down [hold down escape (Osae-komi-toketa)].

\subsubsection{Validity of the Judo Specific Test Proposal}

The study published by the authors was aimed, among other purposes, to validate their judo specific test proposal. Intending to serve that purpose, the authors signal that the judo specific test proposal is significantly correlated with three physical performance evaluation non judo specific tests. 1) the Australian shuttle run test described by Cazorla et al. (2004) that deals with anaerobic power $(R=0.89, p<0.01)$ and with anaerobic capacity $(R=0.86, p<0.001), 2)$ the multistage fitness test of Léger et al. (1984) that deals with the mean maximal heart rate $(R=0.88, p<0.01)$; and 3$)$ the vertical jump test of Sargent (1921) that deals with maximal anaerobic muscular power $(R=0.52, p<0.01)$.

Validity is the degree to which a test or test item measures what it is supposed to measure; it is the most important characteristic of testing [12].

Speaking of the maximal anaerobic power, the authors are right thinking that shortening the duration of the rapid repetitions of one judo technique offbalancing and body positioning by the same practitioner (Uchi-komi) could improve the correlation coefficient $(\mathrm{R}=0.52, \mathrm{p}<0.01)$. However, the judo specific test proposal authors were not aimed at elaborating a test strongly correlated with one or other of commonly used performance evaluation tests: the aim was to elaborate a test that could allow to know, before the competition, whether the judo practitioner organism is ready to enter the competition with sufficient chances of success (has the judo practitioner physical fitness level improved, worsened, or stayed the same?).

The reason why the test proposed and the other three evaluation tests are significantly correlated may possibly be underlay by the fact that each of the four tests resorts more to the lower limbs than to the upper limbs.

Thus, the judo specific test proposal is possibly not valid when utilized in judo practitioners whose favorite techniques (Tokui-waza) do not comprise neither 
the two techniques that the test proposal imposes [the shoulder throw (Seoinage) and the sleeve lifting and pulling hip throw (Sode-tsuri-komi-goshi)] nor similar judo techniques.

\subsection{Conclusion of the Article Here Commented}

In the conclusion of their article, the authors summarize arguments that, according to them, allow them state the representativeness, the sensitivity and the validity of the judo specific test proposal they have elaborated. Their field test is said close to what occurs during a judo fight, among other things, work and rest sequences.

However, during a judo fight, the practitioner who is attempting an attack by means of a judo technique (Tori) no abandon so easily the grip style ( $\mathrm{Ku}$ mi-kata) as is the case in the judo specific test proposal where one first holds a not worn judo jacket (Judogi); next abandon the first hold to go and make a second one on the Judogi worn by the first practitioner on which is being attempted an attack by means of a judo technique (Uke); and then interrupt the second hold to make the third one on the Judogi worn by the second Uke.

Moreover, it is rare, during a fight, at the first attempt, that Uke be thrown or loses sufficiently his balance. As a matter of fact, that often requires the utilization of linked up techniques. Meanwhile, the test imposes separately the shoulder throw (Seoi-nage) and the sleeve lifting and pulling hip throw (Sode-tsurikomi-goshi), none of both in linked up actions.

The authors say that the subjects experience during the judo specific test proposal, judo activity specific actions, for example, technically speaking, techniques specificity, techniques variation and linked up actions.

Apart from the run between the places where are placed the three judo jackets (Judogi) [two worn by practitioners on which are being attempted attacks by means of judo techniques ( $U k e$ ) and one not worn], the actions resorted to during the execution of the test proposal are specific to judo activity [the grip style (Kumi-kata), the shoulder throw (Seoi-nage), and the sleeve lifting and pulling hip throw (Sode-tsuri-komi-goshi)]. Nevertheless, techniques variety leaves something to add. In fact, the test imposes only two throwing techniques while judo is comprised of dozens of techniques: leaving aside receiving or break fall techniques (Ukemi), blocks and parries (Uke-waza), body striking techniques (Atemi-waza), judo comprises dozens of throwing techniques (Nage-waza) [hand throwing techniques (Te-waza), hip throwing techniques (Koshi-waza), foot and leg throwing techniques (Ashi-waza), front sacrifice throwing techniques (Mae-sutemi-waza), side sacrifice throwing techniques (Yoko-sutemiwaza)], hold downs, pins or mat-holds techniques (Osae-komi-waza), arm locks (Kansetsu-waza $=$ Kwansetsu-waza $)$ techniques, as well as choke holds and strangleholds techniques (Shime-waza).

As for linked up actions, what has been said above remains valid: the facet of linked up techniques should be improved. 
According to the authors, the test shows an amount of sensitivity.

As aforementioned, the stated sensitivity does exist but is shown when opposing elite subjects to sub-elite subjects while it should deal with parameters (strength, speed, power, flexibility and agility) that must show values required for a practitioner to take part in a competition.

The authors say that their test proposal is usable as an indicator of the judo practitioner physical fitness level. The test should thus, according to the authors, be helpful in monitoring the physical fitness level, in adjusting the practitioner physical preparation better than laboratory tests.

However, there persists the possibility that the test fails in the purpose for which it was elaborated in the case that, on the one hand, the practitioner favorite techniques (Tokui-waza) and, on the other hand, the two techniques imposed by the test [the shoulder throw (Seoi-nage) and the sleeve lifting and pulling hip throw (Sode-tsuri-komi-goshi)] resort to groups of anatomical structures (muscles, bones and joints) differing from one another.

That poses a real risk of not showing the actual physical fitness level of the judo practitioner, and of not contributing substantially to monitoring the practitioner physical fitness so as to adjust the practitioner physical preparation.

The judo specific test is said valid.

That was one of the objectives to be achieved by the authors of the study that published the judo specific test proposal here concerned.

If to validate is to prove that something is correct and if something correct is suitable for a particular situation [13], the test needs to be improved from the standpoint of validation. As a matter of fact, as developed above, the test does not take the existence of judo practitioner favorite techniques (Tokui-waza) into account.

\section{Conclusions}

The Almansba, Franchini and Sterkowicz judo specific test proposal (2007) is usable all alone instead of three tests, none of the three judo specific: the vertical jump test of Sargent (1921), the multistage fitness test of Léger et al. (1984) and the Australian shuttle run test described by Cazorla et al. (2004) (Table 1). The proposal is thus, to date, the most specific and economic usable to assess the suitability of judo practitioners to meet the competition demands.

However, efforts to increase the test proposal specificity would better lead to test individualization as in judo trained individuals have favorite techniques (Tokui-waza) they use in preference to others. To meet that purpose, the judo specific test proposed by Almansba, Franchini and Sterkowicz (2007) could be utilized as a template for elaborating individualized tests specific to each judo practitioner, comprising only individual favorite standing and/or ground linked up techniques ( Tokui-waza).

The rapid repetitions of one judo technique off-balancing and body positioning by the same practitioner (Uchi-komi) could better be replaced by continual 
Table 1. The four tests that have been utilized to measure or estimate practitioners judo physiological variables values and the processes involved in them.

\begin{tabular}{|c|c|c|c|c|c|}
\hline \multirow[b]{2}{*}{ Tests } & \multicolumn{4}{|c|}{ Physiological variables } & \multirow[b]{2}{*}{ Processes } \\
\hline & $\begin{array}{c}\text { Anaerobic } \\
\text { capacity }\end{array}$ & $\begin{array}{c}\text { Anaerobic } \\
\text { power }\end{array}$ & $\begin{array}{l}\text { Maximal } \\
\text { anaerobic } \\
\text { muscular } \\
\text { power }\end{array}$ & $\begin{array}{c}\text { Mean } \\
\text { maximal } \\
\text { heart rate }\end{array}$ & \\
\hline $\begin{array}{l}\text { Vertical jump test } \\
\text { of Sargent (1921) }\end{array}$ & & & $\begin{array}{l}\text { in lower } \\
\text { limbs, }+\end{array}$ & & jumps \\
\hline $\begin{array}{l}\text { Multistage fitness test of } \\
\text { Léger et al. (1984) }\end{array}$ & & & & + & running \\
\hline $\begin{array}{l}\text { Australian shuttle run test } \\
\text { described by Cazorla et al. } \\
\text { (2004) }\end{array}$ & + & + & & + & running \\
\hline $\begin{array}{c}\text { Almansba, Franchini and } \\
\text { Sterkowicz judo specific test } \\
(2007)\end{array}$ & + & + & + & + & $\begin{array}{l}\text { Uchi-komi, a } \\
\text { judo specific } \\
\text { exercise }\end{array}$ \\
\hline
\end{tabular}

Table 2. Uchi-komi compared with Kakari-geiko.

\begin{tabular}{ccc}
\hline & Uchi-komi & Kakari-geiko \\
\hline Feet movements & $\begin{array}{c}\text { Of Tori: only the foot that is not } \\
\text { on Toris rotation axis } \\
\text { Of Uke: none }\end{array}$ & Of both Toriand Uke: free \\
$\begin{array}{c}\text { Judo attacking techniques } \\
\text { utilized by Tori on Uke }\end{array}$ & only one & not limited \\
$\begin{array}{c}\text { Possibility of linking up judo } \\
\text { techniques by Tori } \\
\text { Possibility of } \text { Uke to } \\
\text { anticipate judo attacking } \\
\text { techniques from Tori }\end{array}$ & unavailable & available \\
\hline
\end{tabular}

completions of variable judo techniques by the same practitioner (Kakari-geiko), another judo exercise which, contrary to Uchi-komi, allows the practitioner who is attempting an attack by means of a judo technique (Tori) to utilize linked up techniques (Table 2).

\section{Conflicts of Interest}

The author declares no conflicts of interest regarding the publication of this paper.

\section{References}

[1] Almansba, R., Franchini, E. and Sterkowicz, S. (2007) Uchi-komi avec Charge, Une Approche Physiologique d'Un Nouveau Test Spécifique au Judo. Science \& Sports, 22, 216-233. https://doi.org/10.1016/j.scispo.2007.06.006

[2] Weers, G. (1997) Skill Range of the Elite Judo Competitor. http://judoinfo.com/weers1.htm 
[3] Thomas, P., Goubault, C., Beau, M.C. and Brandet, M.J.P. (1989) Test d'Adaptation au Judo Dérivé du Léger-Mercier. Médecine du Sport, 63, 286-288.

[4] McArdle, W., Katch, F. and Katch, V. (2001) Physiologie de l'Activité Physique. Énergie, Nutrition et Performance. Maloine, Paris.

[5] Blais, L. and Trilles, F. (2006) The Progress Achieved by Judokas after Strength Training with a Judo-Specific Machine. Journal of Sports Science and Medicine, 5 CSSI, 132-135. http://www.jssm.org/combat/1/17/v5combat-17text.php

[6] Imamura, R.T., Hreljac, A., Escamilla, R.F. and Edwards, W.B. (2006) A ThreeDimensional Analysis of the Center of Mass for Three Different Judo Throwing Techniques. Journal of Sports Science and Medicine, 5 CSSI, 122-131. http://www.jssm.org/combat/1/16v5combat-16text.php

[7] Almansba, R., Franchini, E., Sterkowicz, S., Imamura, R.T., Calmet, M. and Ahmaidi, S. (2008) A Comparative Study of Speed Expressed by the Number of Throws between Heavier and Lighter Categories in Judo. Science \& Sports, 23, 186-188. https://doi.org/10.1016/j.scispo.2007.10.014

[8] Robert, L. (1971) Le Guide Marabout du Judo. Éditions Gérard \& Co, Verviers.

[9] Burke, E.R., Faria, I.E. and White, J.A. (1996) Cycling. In: Reilly, T., Secher, N., Snell, P. and Williams, C., Eds., Physiology of Sports, E \& FN Spon, London, 173-213.

[10] Wikipedia, the Free Encyclopedia (2008) Judo Technique. http://en.wikipedia.org/w/index.php?title=Judo_technique\&oldid=257980706

[11] Ackland, T.R., Kerr, D.A. and Newton, R.U. (2009) Modifying Physical Capacities. In: Ackland, T.R., Elliot, B.C. and Bloomfield, J., Eds., Applied Anatomy and Biomechanics in Sport, Human Kinetics, Champain, 227-276.

[12] Harman, E. (2008) Principles of Test Selection and Administration. In: Baechle, T.R. and Earle, R.W., Eds., Essentials of Strength Training and Conditioning, Human Kinetics, Champain, 237-247.

[13] Summers, D. (2003) Longman Dictionary of Contemporary English. Pearson Education, Essex. 